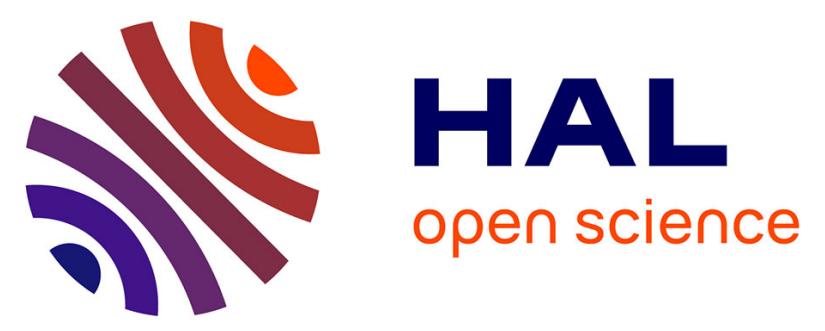

\title{
Formation of local spin-state concentration waves during the relaxation from photoinduced state in a spin-crossover polymer
}

Céline Mariette, Elzbieta Trzop, Serhane Zerdane, Pierre Fertey, Daopeng Zhang, Francisco J Valverde-Muñoz, José-Antonio J Real, Eric Collet

\section{To cite this version:}

Céline Mariette, Elzbieta Trzop, Serhane Zerdane, Pierre Fertey, Daopeng Zhang, et al.. Formation of local spin-state concentration waves during the relaxation from photoinduced state in a spin-crossover polymer. Acta crystallographica Section B: Structural crystallography and crystal chemistry, 2017, 73 (4), pp.660-668. 10.1107/S2052520617007685 . hal-01552077

\section{HAL Id: hal-01552077 \\ https://hal.science/hal-01552077}

Submitted on 30 Jun 2017

HAL is a multi-disciplinary open access archive for the deposit and dissemination of scientific research documents, whether they are published or not. The documents may come from teaching and research institutions in France or abroad, or from public or private research centers.
L'archive ouverte pluridisciplinaire HAL, est destinée au dépôt et à la diffusion de documents scientifiques de niveau recherche, publiés ou non, émanant des établissements d'enseignement et de recherche français ou étrangers, des laboratoires publics ou privés. 


\section{Formation of local spin-state concentration waves during the relaxation from photoinduced state in a spin-crossover polymer}

Authors

\section{Céline Mariette ${ }^{a}$, Elzbieta Trzopa ${ }^{a}$, Serhane Zerdane ${ }^{a}$, Pierre Fertey ${ }^{b}$, Daopeng Zhang ${ }^{\text {cd }}$,} Francisco J. Valverde-Muñoz ${ }^{\mathfrak{c}}$, José-Antonio Real ${ }^{\mathrm{c}}$ and Eric Collet ${ }^{\mathrm{a} *}$

anstitut de Physique de Rennes, UMR 6251, Univ Rennes 1, CNRS, Campus de Beaulieu, Rennes, 35042, France

b Synchrotron SOLEIL, BP 48, L'Orme des Merisiers, Saint Aubin, Gif-sur-Yvette Cedex, 91192, France

'Instituto de Ciencia Molecular (ICMol), Universidad de Valencia, C/ Catedrático José Beltrán Martínez 2, Paterna, 46980, Spain

${ }^{\mathrm{d} C o l l e g e}$ of Chemical Engineering, Shandong University of Technology, Zibo, 255049, People's Republic of China

Correspondence email: eric.collet@univ-rennes1.fr

Synopsis We study how broken symmetry and spin-state concentration waves compete during the relaxation from photoinduced high spin to ground low spin phase of a 2D spin-crossover polymer.

Abstract We report on the complex relaxation from the photoinduced high-spin phase (PIHS) to the low spin phase of the bimetallic 2D coordination spin-crossover polymer $\left[\mathrm{Fe}\left[\left(\mathrm{Hg}(\mathrm{SCN})_{3}\right)_{2}\right]\left(4,4^{\prime} \text { 'bipy }\right)_{2}\right]_{\mathrm{n}}$. During the thermal relaxation, commensurate and incommensurate spin-state concentration wave's (SSCW) form. However, contrary to the steps forming at thermal equilibrium, associated with long-range SSCW order, the SSCWs forming during the relaxation from the PIHS phase correspond to short-range order, revealed by diffuse X-ray scattering. We interpret this as resulting from the competition between the two types of SSCW orders and another structural symmetry breaking, due to ligand ordering, occurring at low temperature and precluding long-range SSCW order.

Keywords: Photo-crystallography; Phase transition; Aperiodicity; Symmetry breaking. 


\section{Introduction}

Advanced crystallography methods have played an important role in material science for connecting their macroscopic properties to microscopic physics or chemistry. It is fair to say that with this regard Philip Coppens has been pioneering different types of developments and applications of the field, such as X-ray charge-density analysis (Koritsanszky \& Coppens, 2001). In relation with the present research paper, we can also mention the importance of photo-crystallography and its extension to the time domain (Kim et al., 2002, Chen et al., 2003, Coppens et al., 2010, Coppens, 2015) or the investigation of aperiodic structural modulation, at the origin of unusual electrical conductivity in $\beta$-(BEDT-TTF $)_{2} I_{3}$ (Leung et al., 1985) for example.

Among a wealth of materials, showing various types of functions related to structural reorganizations, and which can be driven by external stimuli, spin-crossover (SCO) molecular crystals (Halcrow, 2013, Real et al., 2005, Bousseksou et al., 2011) are very interesting in terms of structural science related to the emergence of functions. These molecular systems are made up of transition metal atoms in a ligand field, showing bistability between a low (LS) and a high spin (HS) states. A thermal conversion from LS to HS states can occur, as high temperature favors the HS state of higher entropy (Gutlich \& Hauser, 1990). Because of the electronic redistribution, the HS state is less bonding and corresponds to a higher molecular volume, due to an important metal-ligand bond elongation (Huby et al., 2004, Pillet et al., 2004, Guionneau, 2014, Kusz et al., 2001, Collet et al., 2006, Collet et al., 2009). This structural deformation, involving macroscopic volume change, plays an important role for the light-induced electronic spin state trapping (LIESST) as well as reverse-LIESST (Decurtins et al., 1985, Goujon et al., 2008, Marchivie et al., 2002, Trzop et al., 2007, Clements et al., 2016, Hauser, 1986). Timeresolved structural studies, including femtosecond XANES and picosecond X-ray diffraction, have shown that SCO crystals excited by a femtosecond laser pulse undergo a complex out-of-equilibrium dynamics. The molecular structural trapping occurs at the molecular level on the $100 \mathrm{fs}$ timescale (Cammarata et al., 2014, Bertoni et al., 2012, Bertoni, Cammarata, et al., 2015, Lemke et al., 2017, Zhang et al., 2014, Tissot et al., 2011). It is followed on the ns timescale by lattice expansion, driven by molecular expansion (Bertoni, Lorenc, Cailleau, et al., 2016, Bertoni, Lorenc, et al., 2015) and on the $\mu$ s timescale by lattice heating (Collet, Lorenc, et al., 2012, Bertoni, Lorenc, Graber, et al., 2016). P. Coppens helped us going deeper in the time-domain analysis of the structural changes involved, which is difficult to analyze when the molecular conversion rate is low (Collet, Moisan, et al., 2012).

Materials' response to external stimuli is not always as simple as the sum of independent responses of molecules constituting the crystal. In the case of SCO materials, the molecular packing in crystals is associated with elastic coupling between molecules, mediated over long range through the lattice, which can drive cooperative SCO (Buron-Le Cointe et al., 2012, Tissot et al., 2011, Spiering \& Willenbacher, 
1989, Slimani et al., 2015, Enachescu et al., 2015, Nicolazzi et al., 2008). On short range, the molecular packing and the elastic energy costs, related to important structural changes, can also be at the origin of elastic frustration (Watanabe et al., 2016, Paez-Espejo et al., 2016). It can generate stepwise conversions of the fraction of HS molecules $\gamma_{\mathrm{HS}}$ with temperature, as recently discussed in recent reviews (Shatruk et al., 2015, Ortega-Villar et al., 2016). Structural studies of several $\mathrm{Fe}^{\mathrm{II}}$ systems have reported periodic and aperiodic long-range order of LS and HS states (Boinnard et al., 1994, Chernyshov et al., 2003, Huby et al., 2004, Reger et al., 2001, Money et al., 2007, Luan et al., 2015, Yamada et al., 2006, Sato et al., 2009, Brefuel et al., 2010, Brefuel et al., 2009, Collet, Watanabe, et al., 2012, Bonnet et al., 2008, Clements et al., 2016, Pillet et al., 2012). In addition, similar HS-LS ordering phenomena were reported for a reduced number of $\mathrm{Fe}^{\mathrm{III}}$ (Griffin et al., 2011, Li et al., 2013, Vieira et al., 2013, Murnaghan et al., 2014, Harding et al., 2015) Co ${ }^{\mathrm{II}}$ (Bhar et al., 2012) and $\mathrm{Mn}^{\mathrm{III}}$ (Fitzpatrick et al., 2015) complexes. This long-range ordering of molecules in HS and LS states corresponds to the formation of spin-state concentration waves, i.e. a periodic spatial modulation of the probability for a crystalline site to populate the HS state (Collet, Watanabe, et al., 2012, Marino et al., 2015, Watanabe et al., 2016, Trzop et al., 2016).

We have recently reported a multi-step thermal equilibrium conversion process from complete HS to complete LS phases, in the bimetallic 2D coordination polymer $\left[\mathrm{Fe}\left[\left(\mathrm{Hg}(\mathrm{SCN})_{3}\right)_{2}\right]\left(4,4^{\prime} \text { 'bipy }\right)_{2}\right]_{\mathrm{n}}$ associated with different intermediate phases with different HS-LS long-range orders on the steps. This multi-step conversion shows therefore similar features to Devil's staircase-type phase transition in the

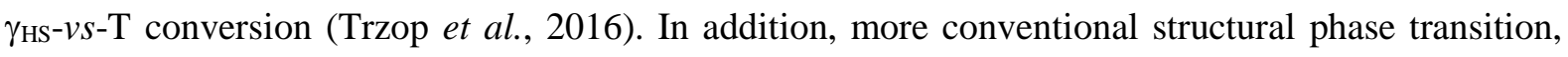
related to symmetry breaking related to molecular distortion and/or ligand ordering, can also occur in SCO materials and be coupled or not to the change of spin state (Watanabe et al., 2013, Brefuel et al., 2010, Brefuel et al., 2009). Here we present a detailed structural analysis of the SCO phenomena in the bimetallic 2D coordination polymer $\left[\mathrm{Fe}\left[\left(\mathrm{Hg}(\mathrm{SCN})_{3}\right)_{2}\right](4,4 \text { 'bipy })_{2}\right]_{\mathrm{n}}(\mathbf{1})$. We briefly summarize thermal equilibrium phase transitions and the structural nature of their changes, to focus on the multi-step relaxation process from the photoinduced HS state.

\section{Phase transitions at thermal equilibrium for (1)}

The multistep spin state conversion of the two-dimensional (2D) bimetallic coordination polymer (1) is illustrated by the thermal dependence of $\chi_{M} \mathrm{~T}$ product $\left(\chi_{M}=\right.$ magnetic susceptibility, $\mathrm{T}$ temperature $)$ shown in Fig. 1. It is governed by the thermal population of the diamagnetic LS and paramagnetic HS states and is consequently scaled to the evolution of the fraction of molecules in the HS state $\gamma_{\mathrm{HS}}$. Magnetic measurements and crystallographic studies revealed different phases and their crystalline structures, already presented in detail elsewhere (Trzop et al., 2016, Zhang, Trzop, Valverde-Muñoz, et al., 2017), are schematically represented in Fig. 1. 


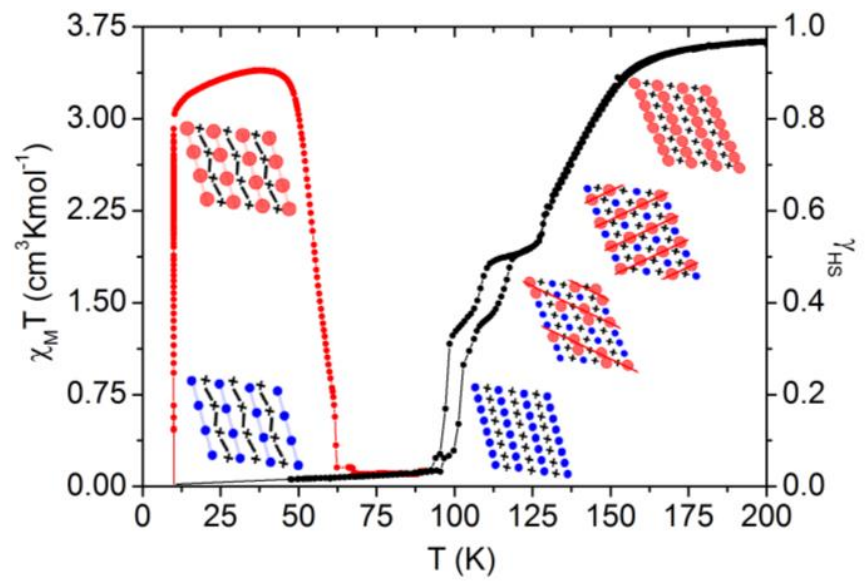

Figure 1 Temperature dependence of $\chi_{\mathrm{M}} \mathrm{T}$ (left axis), scaled to HS fraction $\gamma_{\mathrm{HS}}$ (right axis) in the 10$300 \mathrm{~K}$ range at thermal equilibrium for (1) (black curves) and in the warming mode after photoexcitation at $10 \mathrm{~K}$ by a laser at $660 \mathrm{~nm}$ (red curve). The different structures of the bimetallic coordination polymer made of $\mathrm{Fe}^{\mathrm{II}}$ (HS=red, LS=bleu spheres) and $\mathrm{Hg}^{\mathrm{II}}$ (crosses) connected by (4,4'bipy) ligands (lines) are schematically represented, with stripes (red lines) forming on the steps. The $\chi_{\mathrm{M}} \mathrm{T}$ scaling to $\gamma_{\mathrm{HS}}$ is not valid in the LIESST regime at very low temperature owing to zero field splitting of the paramagnetic HS species.

In the interval $300-190 \mathrm{~K}, \chi_{\mathrm{M}} \mathrm{T} \approx 3.67 \mathrm{~cm}^{3} \mathrm{~K} \mathrm{~mol}^{-1}$ corresponds to a phase where the $\mathrm{Fe}^{\mathrm{II}}$ centers are in the HS ( $\left.\mathrm{S}=2, \gamma_{\mathrm{HS}}=1\right)$ state. This is the high spin (HS) high symmetry (hs) phase $\left(\mathrm{HS}^{\mathrm{hs}} P_{\overline{1}}\right)$. In the crystalline structure, there is a single $\mathrm{Fe}^{\mathrm{II}}$ site lying on an inversion center. In the $\mathrm{HS}^{\text {hs }}$ phase, the asymmetric unit consists of one axially coordinated $\mathrm{N}$ atom belonging to a 4,4'-bipy ligand and two equatorial $\mathrm{N}$ atoms belonging to two crystallographically distinct NCS groups (Figure 2). The average Fe1-N bond length of the $\left[\mathrm{Fe}^{\mathrm{II}} \mathrm{N}_{6}\right]$ octahedron, $\langle\mathrm{Fe} 1-\mathrm{N}\rangle=2.158(3) \AA$, is typical for $\mathrm{Fe}^{\mathrm{II}}$ atoms in the HS state. Below $170 \mathrm{~K}, \chi_{\mathrm{M}} \mathrm{T}$ drops rapidly towards a plateau in the [108-125 K] range, indicating that $50 \%$ of the Fe sites are in the HS and in the LS states. We have shown that a symmetry breaking occurs on the plateau (Trzop et al., 2016). This cell doubling is characterized by the appearance of superstructure Bragg peaks at $\boldsymbol{q}_{c}=\frac{1}{2} \boldsymbol{a}^{*}+\frac{1}{2} \boldsymbol{b}^{*}+\frac{1}{2} c^{*}$, where $\boldsymbol{a}^{*}, \boldsymbol{b}^{*}$ and $\boldsymbol{c}^{*}$ refer to the reciprocal lattice of the high symmetry phase. The structural refinement reveals two different Fe sites: site 1 is mainly LS as characterized by $\langle\mathrm{Fe} 1-\mathrm{N}\rangle \approx 1.962(3) \AA$, whereas site 2 is mainly HS with $\langle\mathrm{Fe} 2-\mathrm{N}\rangle \approx 2.146(3) \AA$. The structure consists then of stripes of molecules in mainly HS or LS states and alternating along $\boldsymbol{q}_{\boldsymbol{c}}$ in a ...HS-LS-HS-LS... sequence (Figure 3,a). This spin-state concentration wave, commensurate with the high symmetry lattice, corresponds to a spatial modulation of the HS fraction:

SSCW ${ }^{\text {com: }} \quad \gamma_{H S}^{c}(\mathrm{r})=\gamma_{H S}^{c}+\left(\eta^{c} / 2\right) \times \cos \left(\boldsymbol{q}_{c} \cdot \boldsymbol{r}\right)$

where X-ray studies give $\gamma_{H S}{ }^{c} \approx 0.5$ and $\eta^{c} \approx 0.9$ (Trzop et al., 2016) at $117 \mathrm{~K}$. 
On cooling further, a second plateau appears in the interval 96-108 $\mathrm{K}$, where an incommensurate modulation appears, characterized by satellite reflections at $\boldsymbol{q}_{i}=0.48 \boldsymbol{a}^{*}+0.35 \boldsymbol{b}^{*}+0.42 c^{*}$. Superspace crystallography evidenced that it corresponds to a phase where the spatial modulation of the HS fraction is incommensurate with the lattice (Figure 3,b). This spin-state concentration wave, incommensurate with the molecular packing, is described as follows:

SSCW ${ }^{\text {incom: }} \quad \gamma_{H S}{ }^{i}(\boldsymbol{r})=\gamma_{H S}{ }^{i}+\left(\eta^{i} / 2\right) \times \cos \left(\boldsymbol{q}_{\boldsymbol{i}} \cdot \boldsymbol{r}\right)$

with $\gamma_{H S}{ }^{i}=0.34$ and $\eta^{i}=0.85$ at $102 \mathrm{~K}$. Since there is no group-subgroup relationship between the $\mathrm{SSCW}^{\mathrm{com}}$ and the $\mathrm{SSCW}^{\text {incom }}$, the transition between the two phases is reconstructive and first-order. These features related to the formation of different long-range ordered HS-LS sequences on the thermal steps present some analogies with Devil's staircase-type transformations (Bak \& von Boehm, 1980, Fisher \& Selke, 1980, Aubry, 1983, Bak \& Bruinsma, 1982, Ohwada et al., 2001, Collet et al., 2001). $q_{s}$ continuously changes from $(0.470 .320 .41)$ at $96 \mathrm{~K}$, to $(0.400 .410 .44)$ at $108 \mathrm{~K}$, above which the locking at $\left(1 / 2 \frac{1}{2} \quad 1 / 2\right)$ occurs (Trzop et al., 2016).

Below $\approx 95 \mathrm{~K}$ the system reaches the low spin phase of high symmetry $\left(\mathrm{LS}^{\mathrm{hs}}\right)$, which is isostructural to the $\mathrm{HS}^{\mathrm{hs}}$ phase. The unique Fe site is now LS with $\langle\mathrm{Fe} 1-\mathrm{N}\rangle=1.961(3) \AA$ at $90 \mathrm{~K}$. Apart from these intra-molecular metric changes, driving volume change, the $\mathrm{LS}^{\text {hs }}$ structure does not present other relevant differences with respect to the $\mathrm{HS}^{\text {hs }}$ structure at $220 \mathrm{~K}$ (Figure 2).

(a)

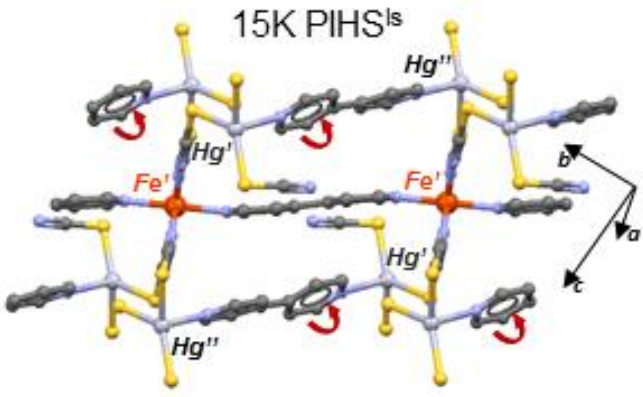

(b)

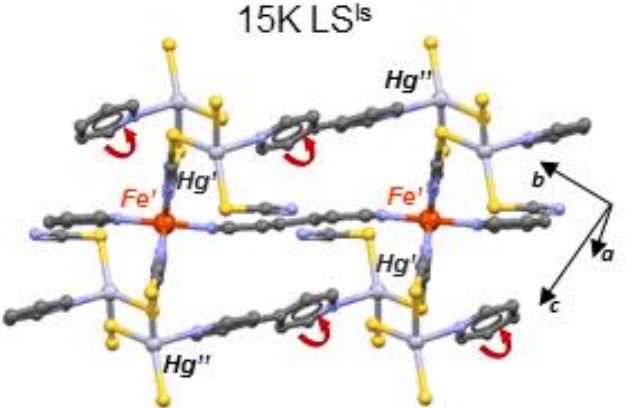

(c)

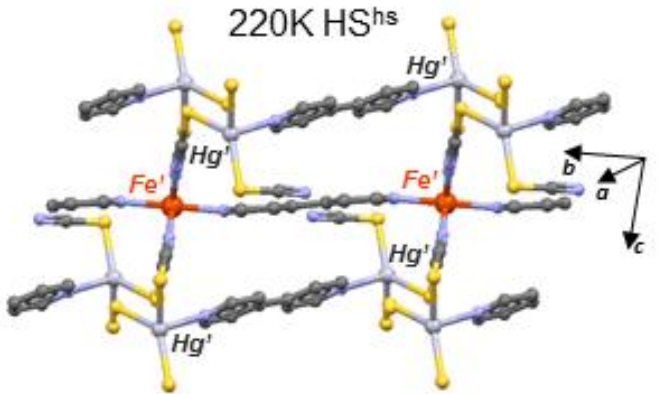

(d)

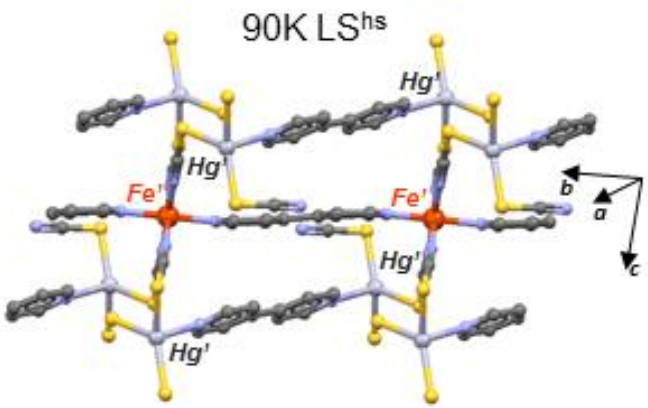

Figure 2 Structures of the isostructural high symmetry $\mathrm{HS}^{\text {hs }}(220 \mathrm{~K})$ and $\mathrm{LS}^{\text {hs }}(90 \mathrm{~K})$ phases and of the isostructural PIHS ${ }^{\mathrm{ls}}(15 \mathrm{~K})$ and $\mathrm{LS}^{\mathrm{ls}}(15 \mathrm{~K})$ phases. The symmetry breaking is associated with ligand ordering (titling of bpy). The unit cell axis are given in the high and low symmetry cells. PIHS ${ }^{1 s}$ and $\mathrm{LS}^{\mathrm{ls}}$ stand for photo-induced HS low symmetry (ls) and LS low symmetry (ls) phases. 
(a)

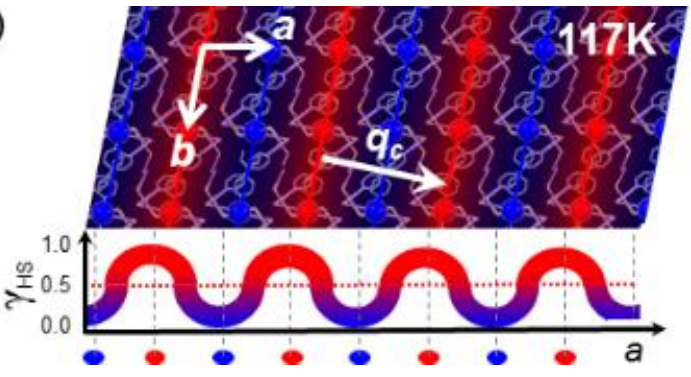

(b)

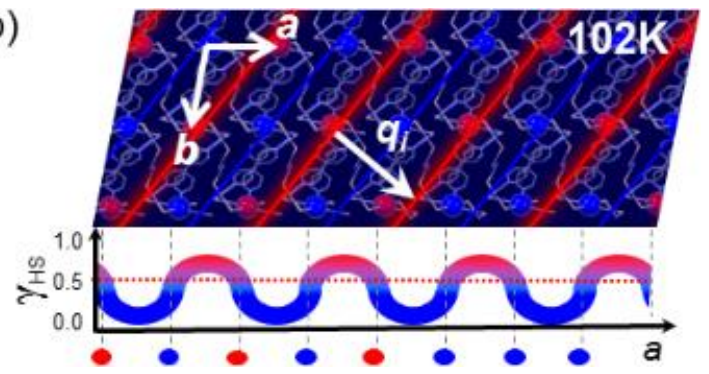

Figure 3 The commensurate spin-state concentration wave $\mathrm{SSCW}^{\mathrm{com}}$ forming along $\boldsymbol{q}_{c}(117 \mathrm{~K}$, left) and incommensurate $\mathrm{SSCW}^{\text {incom }}\left(102 \mathrm{~K}\right.$, right) forming along $\boldsymbol{q}_{i}$ (projected), showing HS (red) and LS (blue) stripes. The scheme below show spatial evolution of $\gamma_{\mathrm{HS}}$ over crystalline sites.

\section{Ligand ordering in low symmetry low spin and photoinduced high spin phases}

Below $85 \mathrm{~K}$, a structural symmetry breaking occurs towards a low symmetry LS phase (LS ${ }^{\text {ls }}$ (Zhang, Trzop, Valverde-Munoz, et al., 2017). It corresponds to another unit-cell doubling with respect to the high symmetry $\mathrm{HS}^{\mathrm{hs}}$ and $\mathrm{LS}{ }^{\mathrm{hs}}$ unit cells, with the appearance of Bragg peaks at $\boldsymbol{q}_{L}=1 / 2 \mathbf{b}^{*}+1 / 2 \mathbf{c}^{*}$. In this doubled unit cell, the $\left[\mathrm{Fe}\left(\mu-4,4^{\prime}-\text { bipy }\right)\right]_{n}{ }^{2+}$ chains are made of non centrosymmetric $\mathrm{Fe}^{\mathrm{II}}$ sites linked by planar centrosymmetric 4,4'-bipy bridges, while the $\left[\left[\mathrm{Hg}(\mathrm{SCN})_{3}\right]_{2}\left(\mu-4,4^{\prime} \text {-bipy }\right)\right]_{2}$ units are constituted of two crystallographically distinct $\mathrm{Hg}(1,2)$ centers bridged by a non centrosymmetric 4,4'-bipy bridge. Consequently, several structural rearrangements occur as shown in Figure 2. The main feature related to this symmetry breaking is the relative twisting of the pyridine rings bridging the two $\mathrm{Hg}$ sites while pyridine rings of Fe sites remain planar in the $\mathrm{LS}^{\mathrm{ls}}$ phase. This is due to the fact that with the cell doubling the inversion symmetry between the pyridine rings connecting the Fe atoms remain, whereas the one between the pyridine rings connecting the $\mathrm{Hg}$ atoms are lost.

We have also reported that the system undergoes LIESST: the magnetic susceptibility of a LS sample at $10 \mathrm{~K}$ increases from $\chi_{\mathrm{M}} \mathrm{T} \approx 0.09 \mathrm{~cm}^{3} \mathrm{~K} \mathrm{~mol}^{-1}$ and saturates around $3.0 \mathrm{~cm}^{3} \mathrm{~K} \mathrm{~mol}^{-1}$ after irradiation with red light ( $\lambda=633 \mathrm{~nm}$ ) (Zhang, Trzop, Valverde-Munoz, et al., 2017). Once the light irradiation is stopped and the temperature is increased, at a rate of $0.3 \mathrm{~K} \mathrm{~min}^{-1}, \chi_{\mathrm{M}} \mathrm{T}$ reaches a maximum around 3.40 $\mathrm{cm}^{3} \mathrm{~K} \mathrm{~mol}^{-1}$ at $38 \mathrm{~K}$. It is characteristic of the thermal population of the different microstates arising from the zero-field splitting of the photoinduced HS phase (PIHS, S = 2). Interestingly, the structure of the photoinduced HS state is not the same as the one of the fully HS state existing at thermal equilibrium above $220 \mathrm{~K}$. Previous photocrystallographic studies have shown that with respect to the HS ${ }^{\text {hs }}$ structure, the photoinduced state has a low symmetry. The structure of this PIHS ${ }^{\text {ls }}$ state is isostructural to the $\mathrm{LS}^{\mathrm{ls}}$ phase, also characterized by the presence of Bragg peaks at $q_{L}=1 / 2 b^{*}+1 / 2 c^{*}$ with respect to the $\mathrm{HS}^{\mathrm{hs}}$. The unit cell also contains a single non-centrosymmetric $\mathrm{Fe}^{\mathrm{II}}$ site with an average $\mathrm{Fe}-\mathrm{N}$ bond length 
$\langle$ Fe1-N $\rangle=2.141(3) \AA$, characteristic of the formation of the HS state. This symmetry breaking is also associated with the twisting of the pyridine rings connecting the $\mathrm{Hg}$ atoms, as for the $\mathrm{LS}^{\mathrm{ls}}$ phase (Figure 2). More details about the $\mathrm{LS}^{\mathrm{ls}}$ and PIHS ${ }^{\mathrm{ls}}$ crystalline structures can be found in (Zhang, Trzop, Valverde-Munoz, et al., 2017).

During the thermal relaxation above $39 \mathrm{~K}$, the magnetic susceptibility drops rapidly and reaches back the initial value characteristic of the LS state around $62 \mathrm{~K}$, indicating a complete relaxation from PIHS to LS states. However, this thermal relaxation does not occur in a single step. The derivative curve (Figure 4) indicates that the relaxation rate is not monotonous, as it is slowing down in the 50-60 K range, where $\gamma_{\mathrm{HS}} \approx 0.5$ and $\gamma_{\mathrm{HS}} \approx 0.33$ are characteristic of steps observed during the thermal crossover, and gets faster around $60 \mathrm{~K}$. It therefore appears of interest to go deeper in the analysis of the relaxation process from the PIHS $^{\mathrm{ls}}$ phase to track the formation of SSCW during the relaxation process and to compare the structural orders with the ones observed at thermal equilibrium.

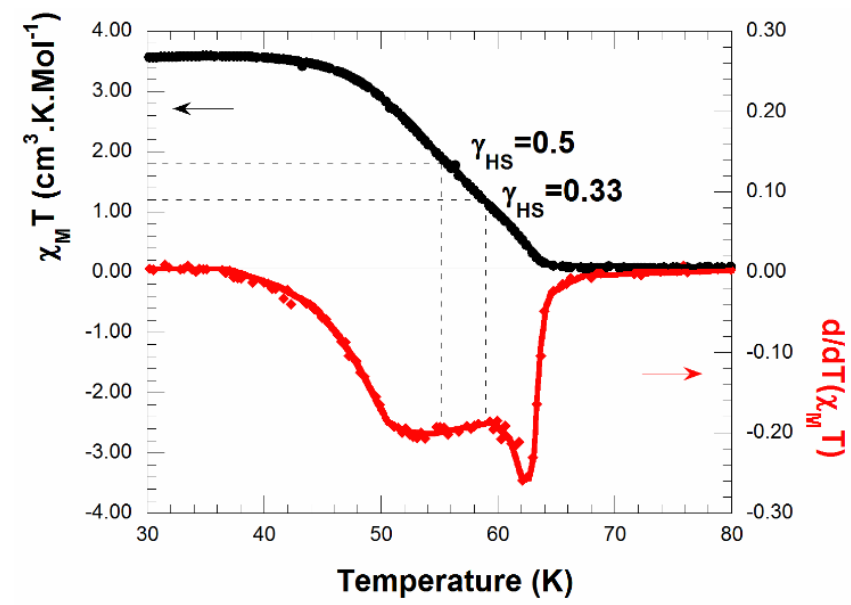

Figure 4 Temperature dependence of $\chi_{\mathrm{M}} \mathrm{T}$ in the $30-80 \mathrm{~K}$ range in the warming mode after photoexcitation at $10 \mathrm{~K}$ by a laser at $633 \mathrm{~nm}$ (black). The derivative with temperature (red) shows a slower relaxation in the $50-60 \mathrm{~K}$ range and a faster relaxation above $60 \mathrm{~K}$ towards the LS state.

\section{Multi-step thermal conversion vs thermal relaxation from photoinduced high spin state}

In order to study in detail the structural changes involved in the processes, we performed X-ray diffraction experiments at synchrotron SOLEIL at the CRISTAL beamline. Single crystal measurements were performed at different temperature, before and after light irradiation. We investigated both the thermal phase transitions and the relaxation process from the PIHS ${ }^{\text {ls }}$ phase through the evolution of the Bragg peaks and diffuse scattering. We used a He-flow cryojet (Cryocool G2b LT from Cryo Industries of America) to cool the sample down to $20 \mathrm{~K}$, where the PIHS ${ }^{1 s}$ phase has a lifetime much larger than $1 \mathrm{~h}$. It is then easy to generate the PIHS ${ }^{\text {hs }}$ state with laser excitation, at 633 or 
$658 \mathrm{~nm}$ (Zhang, Trzop, Valverde-Munoz, et al., 2017) or at $532 \mathrm{~nm}$ in the present work, and to collect then X-ray diffraction data on the diffractometer (Newport-Rigaku Oxford Diffraction, equipped with the Atlas detector). For data analysis, we used the Crysalis software. The wavelength was tuned at $0.513450 \AA$, using a Si 111 double crystal monochromator and sagitale focalization. The unit cell parameters and orientation matrix were refined using CrysAlisPro software (Rigaku, 2015). In order to extract the intensity profile along very precise directions, we adopted a two-step method. After unit cell refinements, parallel $\left(\boldsymbol{a}^{*}, \boldsymbol{b}^{*}\right)$ reciprocal planes were reconstructed with a resolution of $0.002 \AA^{-1}$ along the $b^{*}$ direction. Then, intensity was averaged over 20 unit cells to reconstruct a 3D reciprocal unit. Profiles were extracted after a subsequent refinement of the basis vector in the averaged unit cell. In order to increase the contrast, diffuse scattering profiles were analyzed after filtering from major parasite reflections and Bragg peaks.

The $\mathrm{SSCW}^{\mathrm{com}}$ forming on the plateau at $\gamma_{H S} \approx 0.5$ at thermal equilibrium is characterized by the appearance of superstructure Bragg peaks at $\boldsymbol{q}_{c}=\frac{1}{2} \boldsymbol{a}^{*}+\frac{1}{2} \boldsymbol{b}^{*}+\frac{1}{2} c^{*}$. Figure 5 shows that these superstructure peaks are as sharp as general Bragg peaks and characteristic of a long-range ordered $\mathrm{SSCW}^{\mathrm{com}}$. In a similar way, the satellite reflections at $\boldsymbol{q}_{i}=0.48 \boldsymbol{a}^{*}+0.35 \boldsymbol{b}^{*}+0.42 \boldsymbol{c} *$ (102 K, Figure 5), which appear on the low temperature plateau, are also sharp and related to the aperiodic but long-range SSCW ${ }^{\text {incom }}$. The fit used Gaussian functions with similar FWHM $\left(0.008 \pm 0.002 \AA^{-1}\right)$ for the different peaks. This width is mainly limited by the experimental resolution. It is important to recall that the symmetry at $\mathrm{T}=95 \mathrm{~K}$ is the same as the high symmetry one, which is reflected in the diffraction image by the fact that the scattered intensity at $\boldsymbol{q}_{c}$ and $\boldsymbol{q}_{i}$ completely vanish. Below $85 \mathrm{~K}$, new superstructure Bragg peaks appear at $q_{L}=1 / 2 \mathbf{b}^{*}+1 / 2 \mathbf{c}^{*}$, which are characteristic of the symmetry breaking in the $\mathrm{LS}^{\mathrm{ls}}$ phase, associated with twisting of the pyridine rings. These peaks measured here at $30 \mathrm{~K}$ (Figure 6) are also as sharp as general Bragg peaks, leading us to conclude again to a long-range ligand order at low temperature. The fit in Figure 6 used Gaussian functions for Bragg peaks and superstructure reflections, with similar FWHM $\left(0.007 \pm 0.002 \AA^{-1}\right)$. The later value defines our experimental resolution which is comparable with the one measured on our laboratory set-up.

The photoswitching, evidenced by magnetic measurements, from $\mathrm{LS}^{\mathrm{ls}}$ to $\mathrm{PIHS}^{\mathrm{ls}}$ is characterized by a structural distortion without symmetry breaking. X-ray diffraction measurements allowed to extract a volume increase around $25 \AA^{3}$ (Figure 7), related to the increase of the Fe-N bonds between LS and HS states. This volume change is comparable with the $\approx 35 \AA^{3}$ volume increase from LS (90 K) to HS (300 $\mathrm{K}$ ), which also includes thermal contraction in addition to lattice contraction due to bond shrinking during the spin state conversion. It is responsible for the shift of the Bragg peaks after photo-excitation, as seen in Figure 6. The volume contraction observed on warming is characteristic of the relaxation towards the low spin state and the superstructure peaks at $\boldsymbol{q}_{L}$ indicate the relaxation towards the LS $S^{\mathrm{ls}}$ phase. The volume change in the LS state between 30 and $70 \mathrm{~K}$ corresponds to the expected thermal 
exapnsion. However, the lattice volume in the $55-65 \mathrm{~K}$ range is significantly lower than the volume of the LS state at 30 or $70 \mathrm{~K}$. The $55-65 \mathrm{~K}$ range corresponds to the intermediate state forming during the relaxation. It is very likely that the elastic frustration, at the origin of the formation of (local) SSCW, results in a more compact structure.
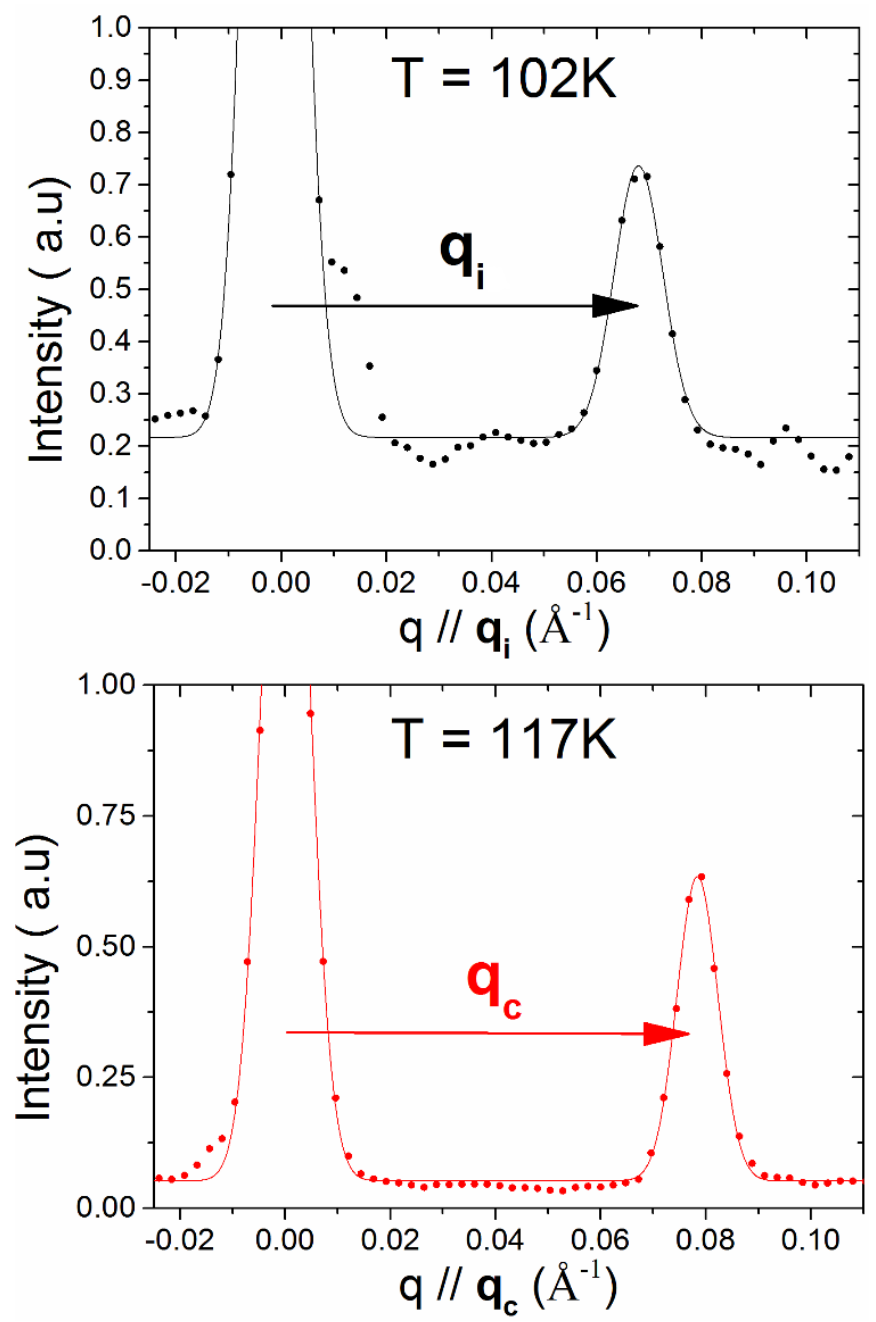

Figure 5 Reconstructed diffracted X-ray intensity in reciprocal spaces, showing sharp superstructure Bragg peaks at $\boldsymbol{q}_{c}=\frac{1}{2} \boldsymbol{a}^{*}+\frac{1}{2} \boldsymbol{b}^{*}+\frac{1}{2} c^{*}$ at $117 \mathrm{~K}$, related to the formation of the $\mathrm{SSCW}^{\mathrm{com}}$ on the plateau where $\gamma_{\mathrm{HS}} \approx 0.5$. The sharp satellite reflections observed at $\boldsymbol{q}_{i}=0.48 \boldsymbol{a} *+0.35 \boldsymbol{b} *+0.42 \boldsymbol{c} *$ at 102 $\mathrm{K}$ are related to the formation of the $\mathrm{SSCW}^{\mathrm{incom}}$ on the plateau where $\gamma_{\mathrm{HS}} \approx 0.34$.

It starts at around $45 \mathrm{~K}$ and goes on in a non-monotonous way up $\approx 60 \mathrm{~K}$, where the initial volume of the LS state is reached anew. The volume change during the relaxation from the photoinduced HS state occurs at temperatures in good agreement with magnetic data (Figure 4), and a kind of plateau or slowing down during the relaxation around 50-55 K. These temperatures correlate well with the magnetic data where the relaxation slows down in this temperature range. 


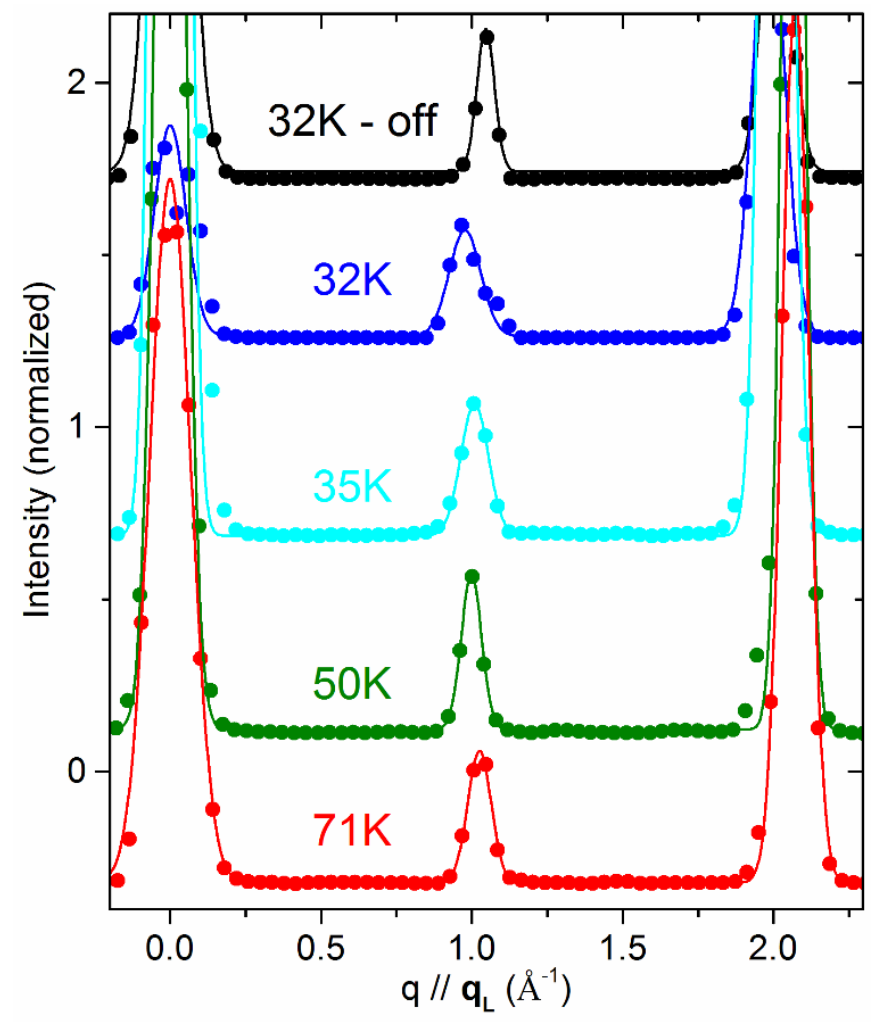

Figure 6 Diffracted X-ray intensity along $\boldsymbol{q}_{L}$ between Bragg peaks, showing similar sharp superstructure peaks at $\boldsymbol{q}_{L}=\frac{1}{2} \boldsymbol{b}^{*}+\frac{1}{2} \boldsymbol{c}^{*}$ at $32 \mathrm{~K}$ in the $\mathrm{LS}^{\mathrm{ls}}$ and PIHS ${ }^{\mathrm{ls}}$ and at higher temperature during the thermal relaxation from PIHS ${ }^{\mathrm{ls}}$ state. The shift of the Bragg peaks along $\boldsymbol{q}_{\boldsymbol{L}}$ from the reference Bragg peak at $\mathrm{q}=0$ is due to lattice expansion at $32 \mathrm{~K}$ before and after laser excitation and contraction during relaxation from PIHS.

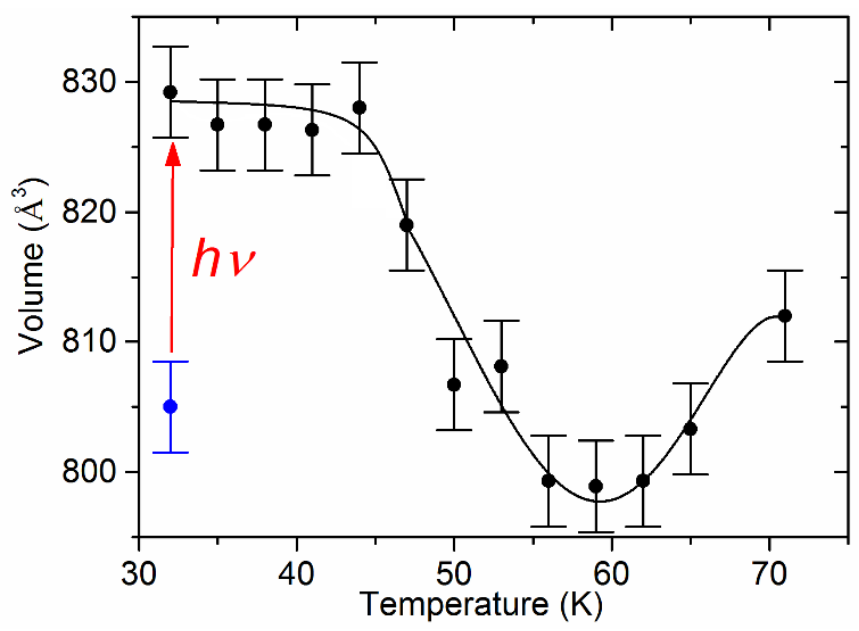

Figure 7 Evolution of the unit-cell volume at $32 \mathrm{~K}$ from $\mathrm{LS}^{\text {ls }}$ to $\mathrm{PIHS}^{\mathrm{ls}}$ with laser irradiation at 532 $\mathrm{nm}$, and during the thermal relaxation towards the $\mathrm{LS}^{\mathrm{ls}}$ at higher temperature. 
The analysis of the diffraction signal in the reciprocal space provides key information on the structural processes involved during the relaxation from the PIHS ${ }^{\mathrm{ls}}$ phase towards the $\mathrm{LS}^{\mathrm{ls}}$ phase. On one hand, it should be underlined that the superstructure Bragg peaks, observed at $\boldsymbol{q}_{L}=1 / 2 \boldsymbol{b}^{*}+1 / 2 \boldsymbol{c}^{*}$, are always present during the relaxation (Figure 6). We could not detect significant change in the width of these superstructure peaks related to the ligand ordering. We therefore conclude that the photo-switching process, which involves mainly $\mathrm{Fe}-\mathrm{N}$ elongation, does not induce ligand disorder. Ligands are probably frozen at such low temperature. On the other hand, we observe important scattering signal around $\boldsymbol{q}_{c}$ and $\boldsymbol{q}_{i}$ during the relaxation process (Figures $8 \& 9$ ). X-ray scattering at these specific positions in the reciprocal space is characteristic of the formation of $\mathrm{SSCW}^{\mathrm{com}}$ and SSCW ${ }^{\text {incom }}$. However, we do not observe sharp satellite or superstructure Bragg peaks, contrary to what is observed at thermal equilibrium (Figure 5). Instead, diffuse scattering is observed around $\boldsymbol{q}_{\boldsymbol{c}}$ and $\boldsymbol{q}_{\boldsymbol{i}}$ in the 47-56 $\mathrm{K}$ range. At $59 \mathrm{~K}$ this diffuse scattering signal around $\boldsymbol{q}_{\boldsymbol{c}}$ and $\boldsymbol{q}_{\boldsymbol{i}}$ disappears.

The diffuse scattering around $\boldsymbol{q}_{\boldsymbol{c}}$ and $\boldsymbol{q}_{i}$ are reminiscence of the spatial fluctuation of the symmetry breaking order parameters and reveal the local formation of the $\mathrm{SSCW}^{\mathrm{com}}$ and $\mathrm{SSCW}^{\text {incom }}$. The coexistence of diffuse signal at both $\boldsymbol{q}$ vector at all temperature results is a complicated peanuts like shape of the diffuse scattering (Figure 8). 3D fitting of this shape with 3 ellipsoids was not possible due to overparametrization. Nevertheless, the resulting isointensity surfaces are well reproduced by considering an isotropic pattern around $\boldsymbol{q}_{\boldsymbol{i}}$ and a disk shaped from around $\boldsymbol{q}_{\boldsymbol{c}}$. Profiles were extracted around $\boldsymbol{q}_{\boldsymbol{i}}$ and $\boldsymbol{q}_{\boldsymbol{c}}$ directions (figure 9). Due to the interpenetration of the ellipsoids, 2 maxima are systematically observed at $\boldsymbol{q}_{\boldsymbol{i}}$ and 3 maxima at $\boldsymbol{q}_{c}$. We used Lorentzian functions to fit the diffuse signal along $q$ :

$$
I(q)=I_{0}+\frac{I_{M}}{1+\left(q-q_{c}\right)^{2} \xi_{i}^{2}}
$$

where $q$ is the absolute scattering vector along the considered direction, $q_{c}$ is the critical vector, and $\xi_{i}$ the correlation lengths along different directions $i$. The broader diffuse scattering at 45 $\mathrm{K}$ corresponds to correlation extending over $\approx 2$ unit cells, whereas the sharper diffuse scattering around $51 \mathrm{~K}$ corresponds to correlation extending over $\approx 11$ unit cells. 

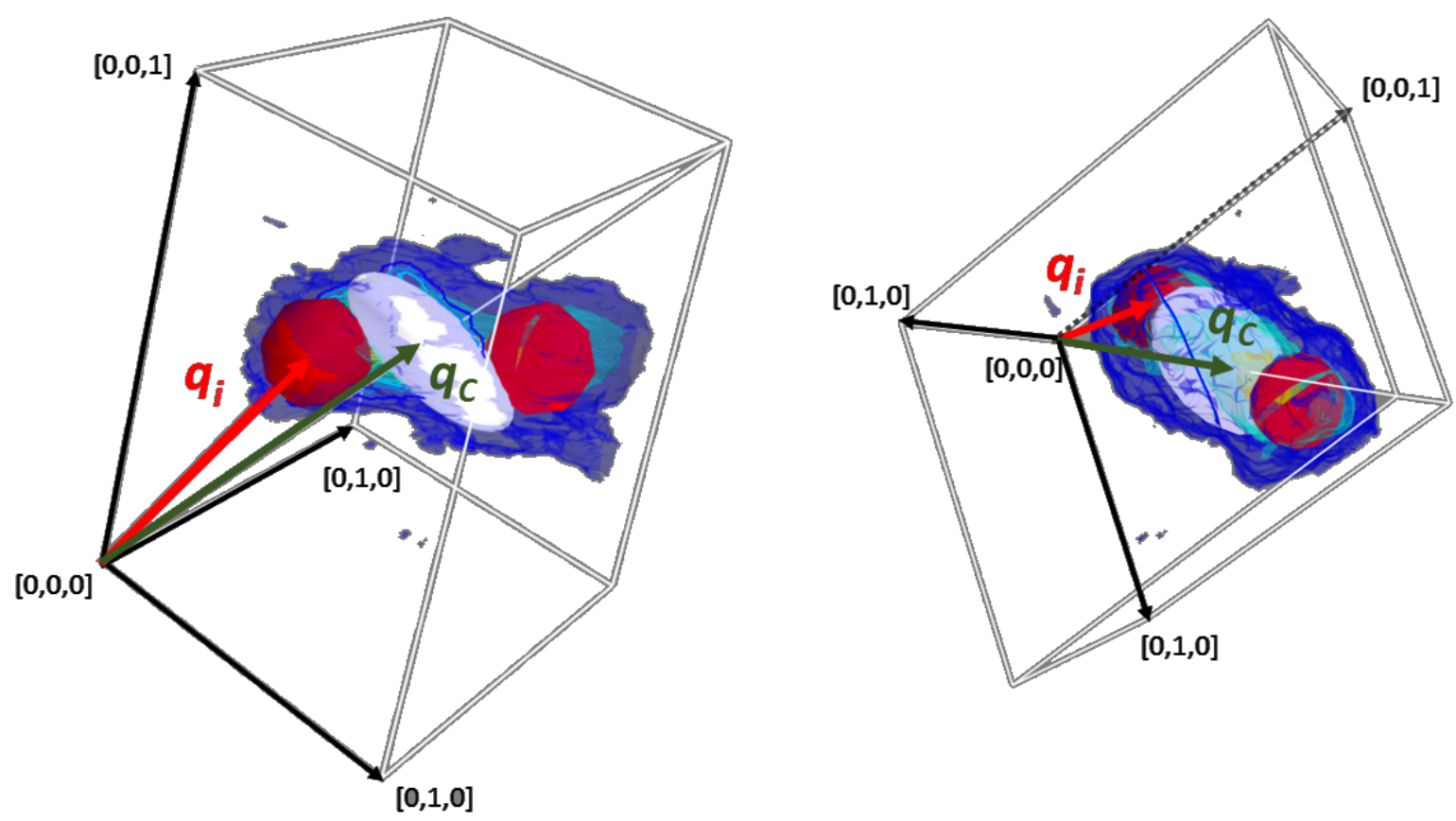

Figure $83 \mathrm{D}$ reconstruction of the diffuse scattering at $\mathrm{T}=53 \mathrm{~K}$. Red sphere and white ellipsoid are constructed to fit the diffuse scattering shape observed around respectively $\boldsymbol{q}_{i}$ and $\boldsymbol{q}_{c}$. The white box represents the edges of the reciprocal unit cell and is given by the position of the general Bragg peaks, which are not shown for clarity. This figure enhances the anisotropic shape of the diffuse X-ray scattering around $\boldsymbol{q}_{c}=\frac{1}{2} a^{*}+\frac{1}{2} b^{*}+\frac{1}{2} c^{*}$ and isotropic shape around $\boldsymbol{q}_{i}=0.48 a^{*}+0.35 b^{*}+0.42 c^{*}$.

This result can be discussed in regard to a previous study of the stepwise relaxation of another SCO material, where clear X-ray diffraction Bragg peaks signing the long-range formation of HS-LS sequence was revealed on the relaxation step (Pillet et al., 2012). Our case constitutes a next step in complexity. The first reason is the multistep ordering happening during the thermal conversion. But the key point is certainly the symmetry breaking, associated with the twist of the ligand, arising at low temperature. This was not the case in the study reported by Pillet et al., where HS and PIHS states had exactly the same symmetry. The symmetry breaking we observe below $85 \mathrm{~K}$ is associated with the ligand ordering along $\boldsymbol{q}_{L}$ and characterized by a first symmetry breaking order parameter. It should be underlined that this symmetry breaking order parameter has different symmetry from the one related to the formation of the $\mathrm{SSCW}^{\text {com }}$ $\left(\boldsymbol{q}_{\boldsymbol{c}}\right)$ or of the $\mathrm{SSCW}^{\text {incom }}\left(\boldsymbol{q}_{i}\right)$. Therefore, reaching the $\mathrm{SSCW}^{\text {com }}$ or SSCW ${ }^{\text {incom }}$ phase from the PIHS $^{\text {ls }}$ phase implies a reconstructive phase transition, as there is no group-subgroup relationship between these phases. 

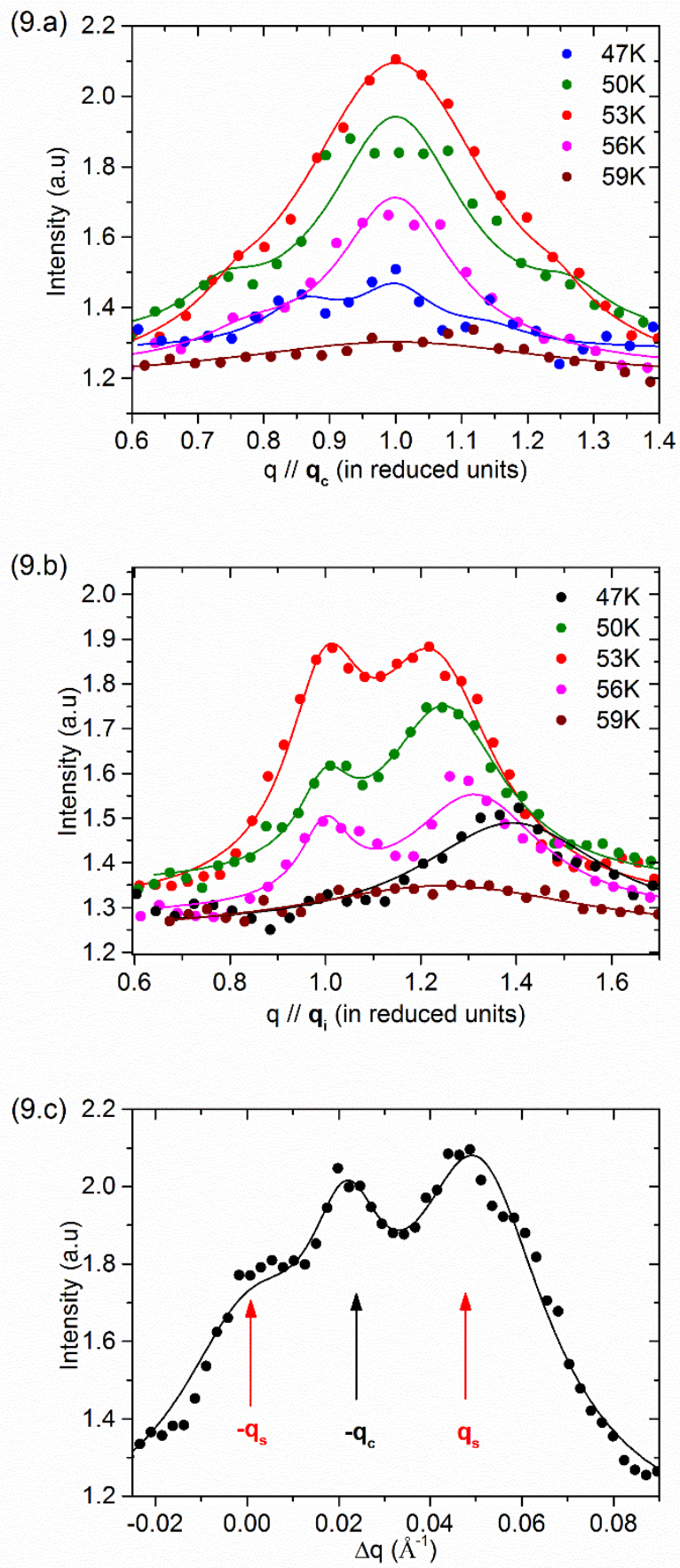

Figure 9 Intensity profiles of the diffuse scattering around $\boldsymbol{q}_{c}=\frac{1}{2} a^{*}+\frac{1}{2} b^{*}+\frac{1}{2} c^{*}$ (9.a) and $\boldsymbol{q}_{i}=$ $0.48 a^{*}+0.35 b *+0.42 c^{*}(9 . b)$ extracted from intensity volume as shown on figure 8 . Continuous lines are the result of a fit with two or three lorentzian functions respectively. Fig. $\mathrm{c}$ show a profile along the direction $\left(+\boldsymbol{q}_{i},-\boldsymbol{q}_{\boldsymbol{i}}\right)$ at $\mathrm{T}=53 \mathrm{~K}$ confirming the presence of 3 maxima. 
Such first-order transition requires important thermal energy. On the other hand, a recent theoretical study underlined that the step may hardly appear during the relaxation process because the long-range HS-LS order is difficult to form (Watanabe et al., 2016). This energy barrier, in addition to the two competing ordering phenomena between the formation of local $\mathrm{SSCW}^{\mathrm{com}}$ (around $\boldsymbol{q}_{\boldsymbol{c}}$ ) and local SSCW ${ }^{\text {incom }}$ (around $\boldsymbol{q}_{\boldsymbol{i}}$ ) explains the local character of the SSCW observed during the relaxation. The fit of the diffuse scattering appears in this case to be very challenging due to strong overlap of the signatures at $q_{c}$ and $q_{s}$. Considering the crystallographic directions, we could estimate the extent of the order between 2 and 11 unit cells depending on the direction and the temperature. One should keep in mind that the proper axis of the diffuse scattering ellipsoid, which cannot be determined precisely for the aforementioned reason, do not lye along the crystallographic directions. The formation of small domains might be explained by mismatch domain walls between $\mathrm{SSCW}^{\mathrm{com}}$ and $\mathrm{SSCW}^{\text {incom }}$ and/ or antiphase boundaries associated with a spatial phase-shift of the SSCW, as represented schematically on figure 10 . These "stacking faults", preclude long-range order.

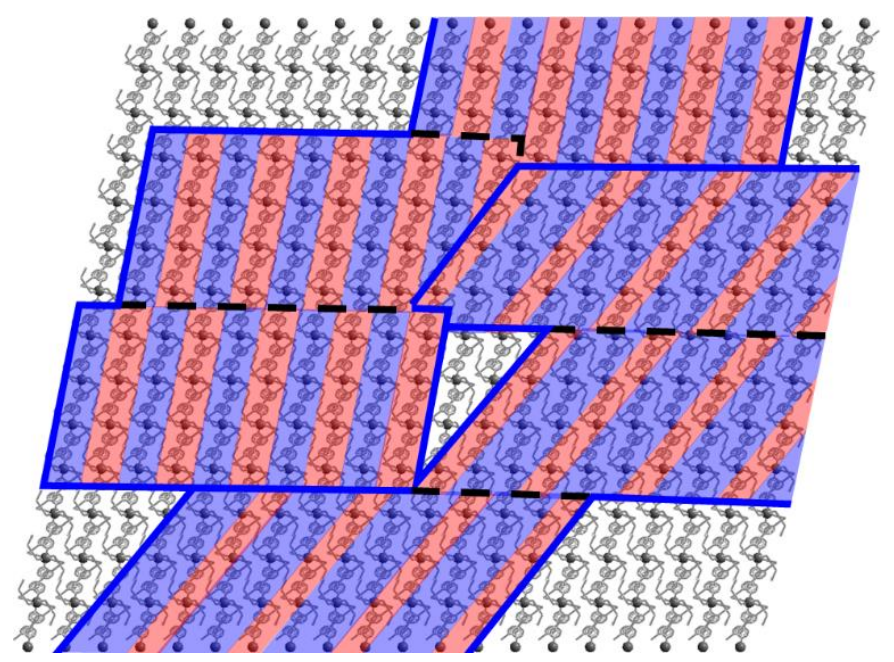

Figure 10 Schematic representation of the formation of locally ordered $\mathrm{SSCW}^{\text {com }}$ where HS

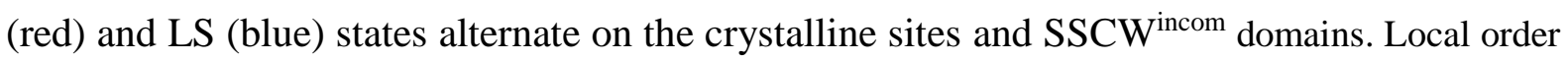
may result from the formation of antiphase boundaries (discontinuous lines) between the same "phases" and domain walls (continuous lines) between $\mathrm{SCCW}^{\mathrm{com}}$ and SSCW ${ }^{\text {incom }}$ domains. 


\section{Conclusion}

Phase transitions related to spin-crossover phenomena, at thermal equilibrium or during the relaxation from photoinduced HS state to LS state, are in most cases single-step and isostructural processes. Sometimes more complicated phase transitions may occur, involving symmetry breaking and/or formation of SSCW. Diffraction techniques are powerful to reveal the nature of the symmetry breaking and the structural changes involved (intra and/or intermolecular). The present study reveals an unusual relaxation process from photoinduced HS state, where HS-LS sequences spatially form, but on short-range order only, as directly evidenced by the appearance of diffuse scattering signal. This type of measurement opens new possibilities to investigate, beyond the average crystalline structure, out-of-equilibrium transformations of materials (Guerin et al., 2010), especially when induced by light excitation.

Acknowledgements This work was supported by the Spanish Ministerio de Economia y Competitividad (MINECO), FEDER (CTQ2013-46275-P and CTQ2016-78341-P), Unidad de Excelencia MDM-2015-0538, the Generalitat Valenciana through PROMETEO/2016/147. F.J.V.M. thanks MINECO for a predoctoral (FPI) grant. D.Z. thanks the support from the Natural Science Foundation of China (21671121). E.T. thanks CNRS for Post-Doc funding. EC thanks the National Research Agency (ANR-13-BS04-0002) and Rennes Metropole for equipment funding.

\section{References}

Aubry, S. (1983). J. Phys. France 44, 147-162.

Bak, P. \& Bruinsma, R. (1982). Physical Review Letters 49, 249-251.

Bak, P. \& von Boehm, J. (1980). Physical Review B 21, 5297-5308.

Bertoni, R., Cammarata, M., Lorenc, M., Matar, S. F., Letard, J. F., Lemke, H. T. \& Collet, E. (2015). Acc Chem Res 48, 774781.

Bertoni, R., Lorenc, M., Cailleau, H., Tissot, A., Laisney, J., Boillot, M. L., Stoleriu, L., Stancu, A., Enachescu, C. \& Collet, E. (2016). Nat Mater 15, 606-610.

Bertoni, R., Lorenc, M., Graber, T., Henning, R., Moffat, K., Létard, J. F. \& Collet, E. (2016). Crystengcomm 18, 7269-7275.

Bertoni, R., Lorenc, M., Tissot, A., Boillot, M. L. \& Collet, E. (2015). Coordination Chemistry Reviews 282-283, 66-76.

Bertoni, R., Lorenc, M., Tissot, A., Servol, M., Boillot, M. L. \& Collet, E. (2012). Angew Chem Int Ed Engl 51, 7485-7489.

Bhar, K., Khan, S., Costa, J. S., Ribas, J., Roubeau, O., Mitra, P. \& Ghosh, B. K. (2012). Angewandte Chemie International Edition 51, 2142-2145.

Boinnard, D., Bousseksou, A., Dworkin, A., Savariault, J. M., Varret, F. \& Tuchagues, J. P. (1994). Inorganic Chemistry 33, 271-281.

Bonnet, S., Siegler, M. A., Costa, J. S., Molnar, G., Bousseksou, A., Spek, A. L., Gamez, P. \& Reedijk, J. (2008). Chem Commun, 5619-5621.

Bousseksou, A., Molnar, G., Salmon, L. \& Nicolazzi, W. (2011). Chemical Society Reviews 40, 3313-3335.

Brefuel, N., Collet, E., Watanabe, H., Kojima, M., Matsumoto, N., Toupet, L., Tanaka, K. \& Tuchagues, J. P. (2010). Chemistry 16, 14060-14068.

Brefuel, N., Watanabe, H., Toupet, L., Come, J., Matsumoto, N., Collet, E., Tanaka, K. \& Tuchagues, J. P. (2009). Angew Chem Int Ed Engl 48, 9304-9307.

Buron-Le Cointe, M., Hébert, J., Baldé, C., Moisan, N., Toupet, L., Guionneau, P., Létard, J. F., Freysz, E., Cailleau, H. \& Collet, E. (2012). Physical Review B 85.

Cammarata, M., Bertoni, R., Lorenc, M., Cailleau, H., Di Matteo, S., Mauriac, C., Matar, S. F., Lemke, H., Chollet, M., Ravy, S., Laulhe, C., Letard, J. F. \& Collet, E. (2014). Physical Review Letters 113, 227402.

Chen, L. X., Shaw, G. B., Novozhilova, I., Liu, T., Jennings, G., Attenkofer, K., Meyer, G. J. \& Coppens, P. (2003). Journal of the American Chemical Society 125, 7022-7034.

Chernyshov, D., Hostettler, M., Tornroos, K. W. \& Burgi, H. B. (2003). Angew Chem Int Ed Engl 42, 3825-3830.

Clements, J. E., Price, J. R., Neville, S. M. \& Kepert, C. J. (2016). Angew Chem Int Ed Eng/ 55, 15105-15109. 
Collet, E., Boillot, M. L., Hebert, J., Moisan, N., Servol, M., Lorenc, M., Toupet, L., Buron-Le Cointe, M., Tissot, A. \& Sainton, J. (2009). Acta Crystallogr B 65, 474-480.

Collet, E., Buron-Le Cointe, M. \& Cailleau, H. (2006). Journal of the Physical Society of Japan 75, 011002.

Collet, E., Buron-Le Cointe, M., Lemée-Cailleau, M. H., Cailleau, H., Toupet, L., Meven, M., Mattauch, S., Heger, G. \& Karl, N. (2001). Physical Review B 63.

Collet, E., Lorenc, M., Cammarata, M., Guerin, L., Servol, M., Tissot, A., Boillot, M. L., Cailleau, H. \& Buron-Le Cointe, M. (2012). Chemistry-a European Journal 18, 2051-2055.

Collet, E., Moisan, N., Balde, C., Bertoni, R., Trzop, E., Laulhe, C., Lorenc, M., Servol, M., Cailleau, H., Tissot, A., Boillot, M. L., Graber, T., Henning, R., Coppens, P. \& Buron-Le Cointe, M. (2012). Physical Chemistry Chemical Physics 14, $6192-$ 6199.

Collet, E., Watanabe, H., Brefuel, N., Palatinus, L., Roudaut, L., Toupet, L., Tanaka, K., Tuchagues, J. P., Fertey, P., Ravy, S., Toudic, B. \& Cailleau, H. (2012). Phys Rev Lett 109, 257206.

Coppens, P. (2015). Struct Dyn 2, 020901.

Coppens, P., Benedict, J., Messerschmidt, M., Novozhilova, I., Graber, T., Chen, Y. S., Vorontsov, I., Scheins, S. \& Zheng, S. L. (2010). Acta Crystallographica Section A 66, 179-188.

Decurtins, S., Gutlich, P., Hasselbach, K. M., Hauser, A. \& Spiering, H. (1985). Inorganic Chemistry 24, 2174-2178.

Enachescu, C., Nishino, M., Miyashita, S., Boukheddaden, K., Varret, F. \& Rikvold, P. A. (2015). Physical Review B 91, 104102.

Fisher, M. E. \& Selke, W. (1980). Physical Review Letters 44, 1502-1505.

Fitzpatrick, A. J., Trzop, E., Muller-Bunz, H., Dirtu, M. M., Garcia, Y., Collet, E. \& Morgan, G. G. (2015). Chem Commun (Camb) 51, 17540-17543.

Goujon, A., Varret, F., Boukheddaden, K., Chong, C., Jeftić, J., Garcia, Y., Naik, A. D., Ameline, J. C. \& Collet, E. (2008). Inorganica Chimica Acta 361, 4055-4064.

Griffin, M., Shakespeare, S., Shepherd, H. J., Harding, C. J., Letard, J. F., Desplanches, C., Goeta, A. E., Howard, J. A. K., Powell, A. K., Mereacre, V., Garcia, Y., Naik, A. D., Muller-Bunz, H. \& Morgan, G. G. (2011). Angewandte ChemieInternational Edition 50, 896-900.

Guerin, L., Hebert, J., Buron-Le Cointe, M., Adachi, S., Koshihara, S. Y., Cailleau, H. \& Collet, E. (2010). Phys Rev Lett 105, 246101.

Guionneau, P. (2014). Dalton Transactions 43, 382-393.

Gutlich, P. \& Hauser, A. (1990). Coordination Chemistry Reviews 97, 1-22.

Halcrow, M. A. (2013). Spin-crossover materials : properties and applications. Wiley.

Harding, D. J., Phonsri, W., Harding, P., Murray, K. S., Moubaraki, B. \& Jameson, G. N. L. (2015). Dalton Transactions 44, 15079-15082.

Hauser, A. (1986). Chemical Physics Letters 124, 543-548.

Huby, N., Guérin, L., Collet, E., Toupet, L., Ameline, J.-C., Cailleau, H., Roisnel, T., Tayagaki, T. \& Tanaka, K. (2004). Physical Review $B 69$.

Kim, C. D., Pillet, S., Wu, G., Fullagar, W. K. \& Coppens, P. (2002). Acta Crystallographica Section A 58, 5.

Koritsanszky, T. S. \& Coppens, P. (2001). Chemical Reviews 101, 1583-1628.

Kusz, J., Spiering, H. \& Gutlich, P. (2001). Journal of Applied Crystallography 34, $229-238$.

Lemke, H. T., Kjær, K. S., Hartsock, R., Brandt van Driel, T., Chollet, M., Glownia, J. M., Song, S., Zhu, D., Pace, E., Matar, S. F., Nielsen, M. N., Benfatto, M., Gaffney, K. J., Collet, E. \& Cammarata, M. (2017). Nat. Commun. 8, 15342.

Leung, P. C. W., Emge, T. J., Beno, M. A., Wang, H. H., Williams, J. M., Petricek, V. \& Coppens, P. (1985). Journal of the American Chemical Society 107, 6184-6191.

Li, Z.-Y., Dai, J.-W., Shiota, Y., Yoshizawa, K., Kanegawa, S. \& Sato, O. (2013). Chemistry - A European Journal 19, 1294812952.

Luan, J., Zhou, J., Liu, Z., Zhu, B., Wang, H., Bao, X., Liu, W., Tong, M.-L., Peng, G., Peng, H., Salmon, L. \& Bousseksou, A. (2015). Inorganic Chemistry 54, 5145-5147.

Marchivie, M., Guionneau, P., Howard, J. A. K., Chastanet, G., Letard, J. F., Goeta, A. E. \& Chasseau, D. (2002). Journal of the American Chemical Society 124, 194-195.

Marino, A., Buron-Le Cointe, M., Lorenc, M., Toupet, L., Henning, R., DiChiara, A. D., Moffat, K., Brefuel, N. \& Collet, E. (2015). Faraday Discuss 177, 363-379.

Money, V. A., Carbonera, C., Elhaïk, J., Halcrow, M. A., Howard, J. A. K. \& Létard, J.-F. (2007). Chemistry - A European Journal 13, 5503-5514.

Murnaghan, K. D., Carbonera, C., Toupet, L., Griffin, M., Dirtu, M. M., Desplanches, C., Garcia, Y., Collet, E., Letard, J. F. \& Morgan, G. G. (2014). Chemistry-a European Journal 20, 5613-5618.

Nicolazzi, W., Pillet, S. \& Lecomte, C. (2008). Physical Review B 78, 174401.

Ohwada, K., Fujii, Y., Takesue, N., Isobe, M., Ueda, Y., Nakao, H., Wakabayashi, Y., Murakami, Y., Ito, K., Amemiya, Y., Fujihisa, H., Aoki, K., Shobu, T., Noda, Y. \& Ikeda, N. (2001). Phys Rev Lett 87, 086402.

Ortega-Villar, N., Muñoz, C. M. \& Real, A. J. (2016). Magnetochemistry 2.

Paez-Espejo, M., Sy, M. \& Boukheddaden, K. (2016). J Am Chem Soc 138, 3202-3210.

Pillet, S., Bendeif, E.-E., Bonnet, S., Shepherd, H. J. \& Guionneau, P. (2012). Physical Review B 86, 064106

Pillet, S., Hubsch, J. \& Lecomte, C. (2004). The European Physical Journal B 38, 541-552.

Real, J. A., Gaspar, A. B. \& Munoz, M. C. (2005). Dalton Trans, 2062-2079.

Reger, D. L., Little, C. A., Young, V. G. \& Pink, M. (2001). Inorganic Chemistry 40, 2870-2874.

Rigaku (2015). CrysAlisPro 1.171.38.41 or 1.171.37.35h.

Sato, T., Nishi, K., lijima, S., Kojima, M. \& Matsumoto, N. (2009). Inorganic Chemistry 48, 7211-7229.

Shatruk, M., Phan, H., Chrisostomo, B. A. \& Suleimenova, A. (2015). Coordination Chemistry Reviews 289-290, 62-73.

Slimani, A., Boukheddaden, K. \& Yamashita, K. (2015). Physical Review B 92, 014111.

Spiering, H. \& Willenbacher, N. (1989). Journal of Physics: Condensed Matter 1, 10089.

Tissot, A., Bertoni, R., Collet, E., Toupet, L. \& Boillot, M.-L. (2011). Journal of Materials Chemistry 21, 18347.

Trzop, E., Buron-Le Cointe, M., Cailleau, H., Toupet, L., Molnar, G., Bousseksou, A., Gaspar, A. B., Real, J. A. \& Collet, E. (2007). Journal of Applied Crystallography 40, 158-164.

Trzop, E., Zhang, D., Pineiro-Lopez, L., Valverde-Munoz, F. J., Carmen Munoz, M., Palatinus, L., Guerin, L., Cailleau, H., Real, J. A. \& Collet, E. (2016). Angew Chem Int Ed Eng/ 55, 8675-8679. 
Vieira, B. J. C., Coutinho, J. T., Santos, I. C., Pereira, L. C. J., Waerenborgh, J. C. \& da Gama, V. (2013). Inorganic Chemistry 52, 3845-3850.

Watanabe, H., Brefuel, N., Collet, E., Toupet, L., Tanaka, K. \& Tuchagues, J. P. (2013). Eur J Inorg Chem, 710-715.

Watanabe, H., Tanaka, K., Bréfuel, N., Cailleau, H., Létard, J.-F., Ravy, S., Fertey, P., Nishino, M., Miyashita, S. \& Collet, E. (2016). Physical Review B 93.

Yamada, M., Hagiwara, H., Torigoe, H., Matsumoto, N., Kojima, M., Dahan, F., Tuchagues, J.-P., Re, N. \& lijima, S. (2006). Chemistry - A European Journal 12, 4536-4549.

Zhang, D., Trzop, E., Valverde-Munoz, F. J., Piñeiro-López, L., Muñoz, M. C., Collet, E. \& Real, J. A. (2017).

Zhang, D., Trzop, E., Valverde-Muñoz, F. J., Piñeiro-López, L., Muñoz, M. C., Collet, E. \& Real, J. A. (2017). Cryst Growth Des $17,2736-2745$.

Zhang, W. K., Alonso-Mori, R., Bergmann, U., Bressler, C., Chollet, M., Galler, A., Gawelda, W., Hadt, R. G., Hartsock, R. W., Kroll, T., Kjaer, K. S., Kubicek, K., Lemke, H. T., Liang, H. Y. W., Meyer, D. A., Nielsen, M. M., Purser, C., Robinson, J. S., Solomon, E. I., Sun, Z., Sokaras, D., van Driel, T. B., Vanko, G., Weng, T. C., Zhu, D. L. \& Gaffney, K. J. (2014). Nature 509, 345-348. 